\title{
Experimental Research of the Influence of Microfracture Morphology on Permeability of Shale Rock
}

\author{
Xiaohe Huang $\mathbb{D},{ }^{1}$ Yunqian Long $\mathbb{D},{ }^{1}$ Yuyi Wang, ${ }^{1}$ and Ming Yue $\mathbb{D}^{2}$ \\ ${ }^{1}$ School of Petrochemical Engineering \& Environment, Zhejiang Ocean University, Zhoushan 316022, China \\ ${ }^{2}$ School of Civil and Resources Engineering, University of Science and Technology Beijing, Beijing 100083, China \\ Correspondence should be addressed to Yunqian Long; longyunqian@zjou.edu.cn
}

Received 3 February 2021; Revised 16 June 2021; Accepted 23 June 2021; Published 10 July 2021

Academic Editor: Chris Harris

Copyright (C) 2021 Xiaohe Huang et al. This is an open access article distributed under the Creative Commons Attribution License, which permits unrestricted use, distribution, and reproduction in any medium, provided the original work is properly cited.

\begin{abstract}
Hydraulic fracturing is currently one of the main technical methods of shale gas exploitation. The permeability variation of shale gas reservoir after fracturing is inevitable, while the influence of fracture length and fracture width on permeability and seepage characteristics of shale rock is a mystery. Besides, the stress sensitivity characteristics of shale rock, derived from different initial permeability, with the same permeability after fracturing are also ambiguous. To this end, a series of seepage characteristic experiments related to different fracture parameters are carried out with the black shale of the Longmaxi Formation in Sichuan gas field as the research target. The results show that the fracture length and fracture width have a good exponential relationship with the corresponding permeability of the reformed shale rock, and the contribution of the fracture width to shale permeability is much greater than that of the fracture length. In addition, the nonlinear seepage characteristics of shale rock are gradually significant with the reduction of fracture length and fracture width. Taking the primitive effective stress (10 MPa) as a critical point, the permeability of shale with large initial permeability decreased by $26.4 \%$, which is about twice as much as that of shale rock with small initial permeability (14.9\%) in the selected pressure loading stage, owing to the difference of fracture width inside the shale rock. The permeability of the shale rock with a large initial permeability is restored by $14.7 \%$, while the shale rock with a small initial permeability is only recovered to $5.2 \%$ in the pressure unloading stage, which is attributed to the closure of fractures, especially the loss of fracture width. This research can provide some new insights for the production prediction of shale gas reservoir after fracturing.
\end{abstract}

\section{Introduction}

It is well known that shale gas reservoirs are rich in nanomicron pores with low porosity and ultralow permeability [1-3]. In recent years, the successful experience of shale gas reservoir exploitation has shown that fracturing, especially stimulated reservoir volume (SRV), is an effective means to achieve effective production of shale gas reservoirs $[4,5]$. The permeability of natural or induced fractured shale is the key to understand the dynamic shale production after SRV, and it is also an important parameter for evaluating shale gas production $[6,7]$. However, it is a doubt how fracture width and fracture length affect the permeability variation of shale rock and how to further affect the flow characteristics of fluid in shale gas reservoirs. Besides, the influence of effective stress on the similar level permeability of shale rock induced by artificial fracturing appears to be fuzzy.

In comparison with single common fracturing technology, multiple vertical and horizontal complex fractures are formed through SRV in the exploration of unconventional oil and gas resources [8-12]. Up to now, a large number of experimental studies and numerical simulations have been implemented to study the permeability variation of shale caused by hydraulic fracturing. On the one hand, to estimate the relative contribution of both Darcy and diffusive fluxes to total flow in depleted reservoirs, a measuring permeability methodology was used to separate the reduction of permeability with depletion and the increase in permeability associated with Knudsen diffusion and molecular slippage effects at very low pore pressure [13]. To simulate the hydraulicinduced microfractures in the laboratory, a new method on 
the basis of the Brazil splitting test was successfully established to produce microscale fractures in shale rocks [14]. The mineral composition characteristics, reservoir pore, and fracture characteristics of shale were investigated, and the permeability of three types of induced fractures in shale was tested [15]. Gas permeability tests were performed on the fractured cylindrical shale samples under loading and unloading conditions [16]. On the other hand, the coupled model was used to generate typical evolution profiles of shale permeability under stress-controlled conditions for the cases of both gas injection and gas desorption [17]. The derivation of fracture permeability correlation for elastoplastic contact of rough surfaces was presented, and the deformation and permeability change of shale sample containing a single rough-walled fracture were experimentally investigated [18]. A newly dynamic apparent permeability model, coupling poromechanics, sorption-induced strain, and gas slippage, was proposed to effectively reveal the gas flow mechanisms through microfractures of shale [19]. A discrete fracture network model and a single-porosity model were innovatively combined to simulate the pulse-decay experiments using one fractured Barnett shale plug to obtain accurate properties for both matrix and fracture [20]. The 3D spatial fracture-pore fractal dimensions were proposed to predict shale permeability and their effects on fluid flow behaviors [21]. Compared with the conventional permeability reservoir, the permeability of shale rock appears to be significantly influenced by the effective stress [22-26]. However, there is little research on the influence of fracture length and fracture width on shale permeability. For the shale rocks with the similar permeability induced by fracturing technology, pressure-dependent permeability of shale rock might exhibit significant differences in the exploitation process. These above unclear characteristics of permeability variations bring obstacles to the production prediction of shale gas reservoir.

To evaluate the influences of fracture width and fracture length on shale permeability and flow characteristics, a series of macroscopic seepage experiments related to the influence of different fracture lengths and fracture widths on the permeability variation of fractured shale rocks were conducted. In consideration of the brittleness of shale rock, it was critical to maintain one of the two fracture parameters to study the effect of the other variable on permeability of shale rock. The Brazil splitting test could be successfully applied to form different orders of magnitude fractures in shale rocks [14]. Furthermore, a group of artificial fractured shale samples with similar level permeability were selected to study the influence of effective stress coupling conditions on permeability of shale rocks.

\section{Experimental Section}

2.1. Experimental Material. The upper and lower parts of the Lower Silurian Longmaxi Formation are selected from Sichuan Province. The upper part is mostly gray, gray-yellow, or green-yellow shale with siltstone or limestone tumor core, containing a few graptolites; the lower part is black graptolite shale, which contains a lot of graptolite. The shale rocks used in this experiment are all from Longshan No. 1 Well

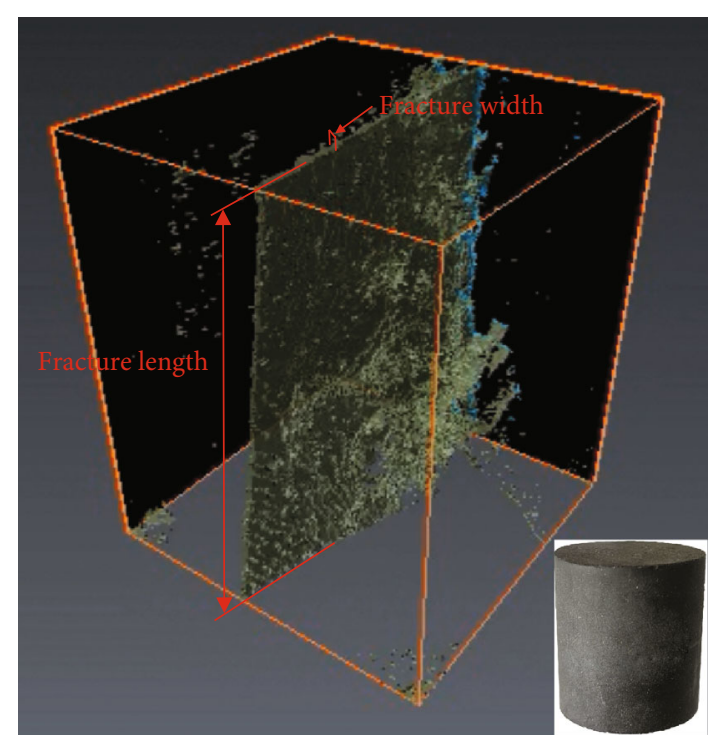

FIgURE 1: Computed tomography image of shale after Brazil splitting test.

and Longshan No. 2 Well, with sampling depths of $900 \mathrm{~m}$ $1800 \mathrm{~m}$. Most importantly, the organic matter in the shale rock is distributed along the microlayer, and the shale rocks are drilled along the parallel bedding direction. Then, the fractures of these rock samples can be artificially generated by the Brazil splitting test, and the morphology and aperture of the internal fractures in the core are exhibited by X-ray microtomography [14]. In addition, the fracture morphology of a selected sample obtained by the CT scanning is shown in Figure 1.

The physical property parameters (fracture length, fracture width, permeability, etc.) of this batch of rock samples before and after fracturing are shown in Table 1 . Ten selected shale rocks are all about $4 \mathrm{~cm}$ in length and $2.5 \mathrm{~cm}$ in width. To study the influences of fracture length and fracture width on permeability variation, the selected shale samples are roughly divided into two categories. In the first category, the shale fractures have similar fracture widths and different fracture lengths. The initial permeability of shale rock ranges from $0.032 \mathrm{mD}$ to $0.1521 \mathrm{mD}$, with an average of $0.0841 \mathrm{mD}$. After fracturing, the permeability of shale rock ranges from $0.107 \mathrm{mD}$ to $2.859 \mathrm{mD}$, with an average of $0.9466 \mathrm{mD}$. In the second category, the shale fractures are similar in length and different in width. The initial permeability of shale rock ranges from $0.00067 \mathrm{mD}$ to $0.0015 \mathrm{mD}$, with an average of $0.0026 \mathrm{mD}$. After fracturing, the permeability of shale rock ranges from $0.349 \mathrm{mD}$ to $7.182 \mathrm{mD}$, with an average of $2.7906 \mathrm{mD}$.

2.2. Experimental Equipment. The schematic diagram of gas permeability measurement and stress sensitive characteristics of shale rock is displayed in Figure 2. This measuring system mainly consists of a nitrogen cylinder, a high precision pressure measuring system, a confining pressure system, back pressure, and gas flowmeter system. The first part is composed of nitrogen cylinder and pressure relief valve, which provides the power for flowing system. The second part 
TABLE 1: Basic parameters of Longmaxi shale rock after fracturing.

\begin{tabular}{|c|c|c|c|c|c|c|}
\hline \multirow{3}{*}{ Core no. } & \multirow{3}{*}{ Length $(\mathrm{cm})$} & \multirow{3}{*}{ Diameter $(\mathrm{cm})$} & \multirow{3}{*}{ Permeability $(\mathrm{mD})$} & \multicolumn{3}{|c|}{ After fracturing } \\
\hline & & & & \multicolumn{2}{|c|}{ Fracture } & \multirow{2}{*}{ Permeability $(\mathrm{mD})$} \\
\hline & & & & Length $(\mathrm{cm})$ & Width $(\mathrm{cm})$ & \\
\hline Ls1-12-4 & 3.97 & 2.52 & 0.032 & 0.55 & 0.02 & 0.107 \\
\hline Ls1-14-3 & 4.05 & 2.48 & 0.0885 & 0.85 & 0.018 & 0.205 \\
\hline Ls1-10-5 & 3.96 & 2.52 & 0.1053 & 1.25 & 0.02 & 0.343 \\
\hline Ls1-2-2 & 4.03 & 2.52 & 0.1521 & 2.45 & 0.019 & 1.219 \\
\hline Ls1-15-1 & 4.04 & 2.52 & 0.0426 & 3.15 & 0.02 & 2.859 \\
\hline Ls2-2-3 & 4.01 & 2.52 & 0.0015 & 2.43 & 0.015 & 0.349 \\
\hline Ls2-6-5 & 3.86 & 2.52 & 0.0028 & 2.44 & 0.022 & 1.228 \\
\hline Ls2-7-4 & 3.44 & 2.51 & 0.0047 & 2.45 & 0.024 & 1.853 \\
\hline Ls2-1-3 & 4.02 & 2.52 & 0.0033 & 2.44 & 0.031 & 3.341 \\
\hline Ls2-16-1 & 3.93 & 2.52 & 0.00067 & 2.45 & 0.035 & 7.182 \\
\hline
\end{tabular}

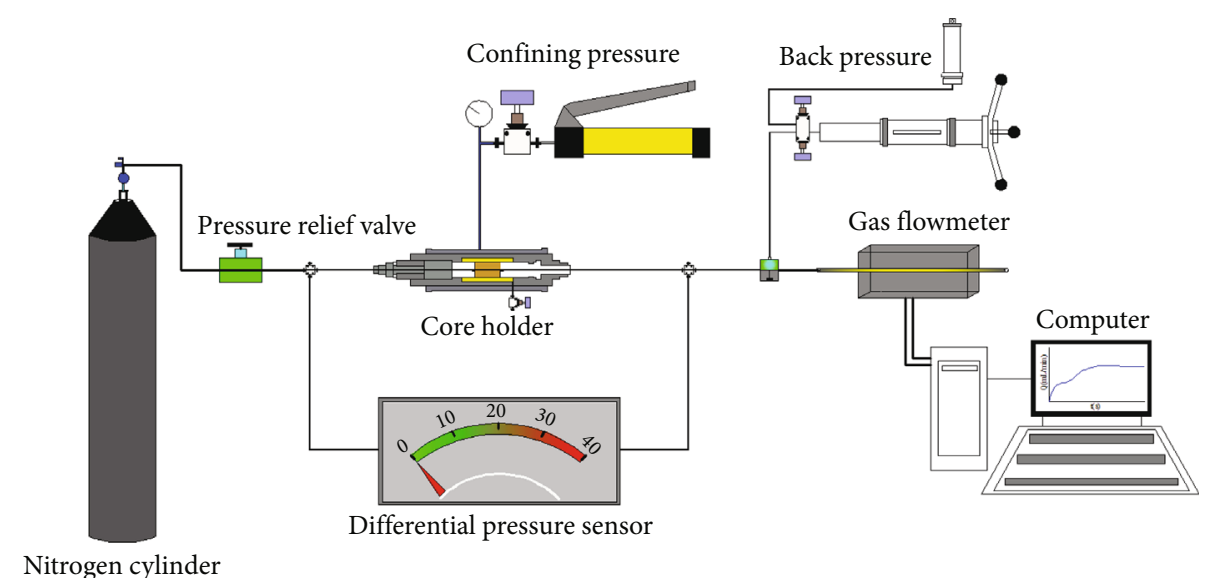

FIgURE 2: Shale gas permeability and stress sensitive characteristic measuring device.

is comprised of core holder, confining pressure, and differential pressure sensor (0.001 40 MPa, Switzerland), which can be utilized to monitor the system pressure variation. The last part consists of back pressure and gas flowmeter $(0.001 \sim 10 \mathrm{~mL} / \mathrm{min}$, China), which is utilized to maintain the pressure of flowing system. It is noted that the whole experiment is carried out with nitrogen gas.

2.3. Experimental Procedure. The seepage characteristics of gas in internal microfracture is measured by high pressure displacement device. Constant pore pressure and changing confining pressure are utilized to evaluate the stress sensitive characteristics of shale rock, and the actual formation conditions are simulated by modifying the effective stress coefficient [27]. The main experimental procedures are as follows:

(a) Tightness Inspection. Connect the pipeline of this experimental device and check the tightness of the pipeline gas

(b) Shale Rock Placement. Put the fractured shale rock bounding with adhesive tape into the gripper and gradually increase the effective confining pressure to $30 \mathrm{MPa}$

(c) Constant Pore Pressure. The gas is injected at a constant low pressure, and the gas flow rate is measured at the outlet until the flow rate is stable. The stable flow rate and corresponding pressure are recorded in turn

(d) Pressurize in Turn. Increase the pressure by one time in turn and inject, repeat the process of (c) until all the set pressure points are determined

(e) Replacement of Shale Rock. The above processes (a)(d) are repeated until the percolation curves of all samples are measured, and the influence of fracture width and fracture length on gas percolation can be analyzed in depth

(f) Pressure-Dependent Permeability Measurement. Taking $2 \mathrm{MPa}$ as the step, the effective stress is slowly increased or decreased, and the permeability under steady state is measured, so as to obtain the stress sensitivity characteristics 


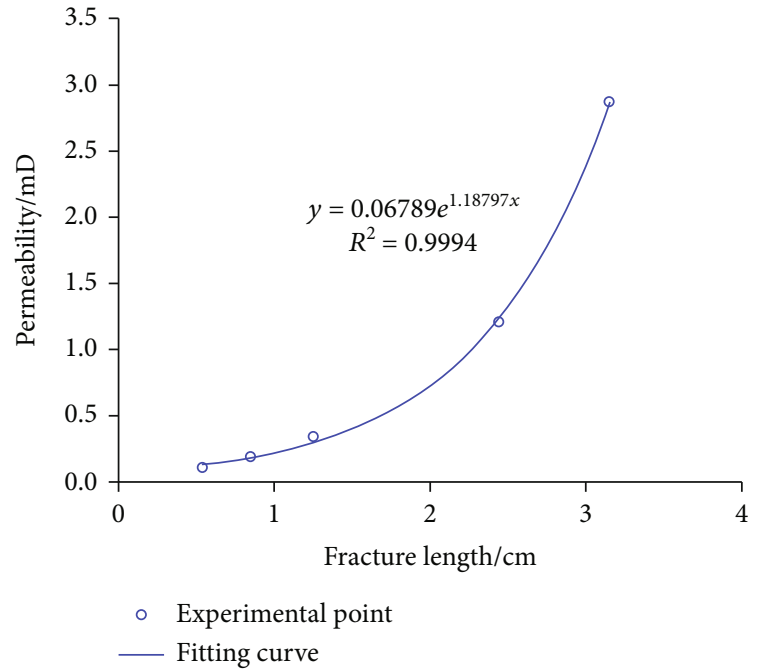

(a)

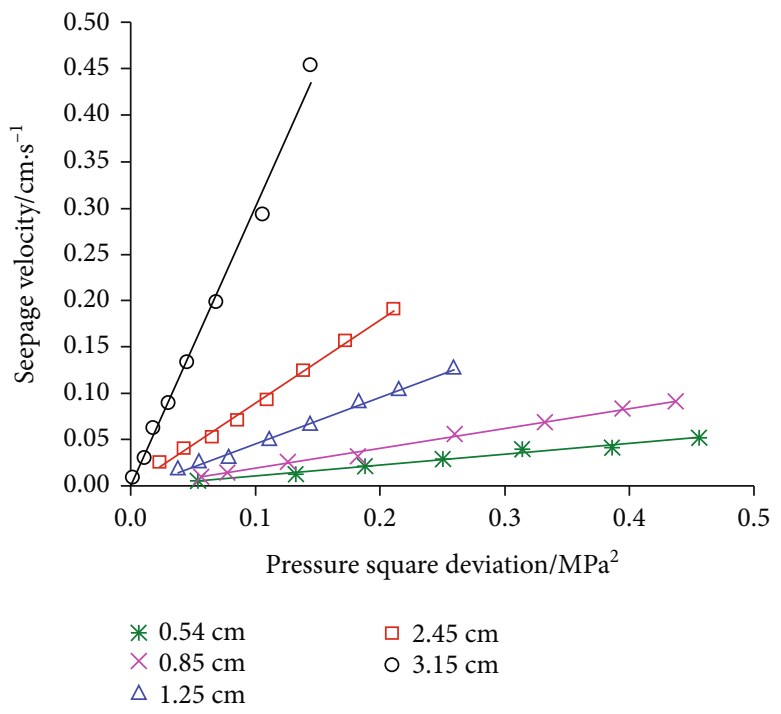

(b)

FIGURE 3: Influence of fracture length on permeability of shale rock: (a) relationship between fracture length and permeability; (b) seepage characteristics of shale with different fracture length.

\section{Results and Discussions}

Based on the dual media permeability model, the fracture length and fracture width are the main parameters determining the permeability variation of shale rock after fracturing. Besides, the fracture directions of the selected shale rocks are roughly the same, which are all parallel to the main seepage directions. Therefore, the effects of fracture length and fracture width on permeability and seepage characteristics of shale rock are discussed in depth. The stress characteristic of shale rock with similar permeability after fracturing is also evaluated.

\subsection{Effect of Internal Microfracture Length on Seepage} Characteristics of Shale Rock. Under the condition of the same fracture width, the permeability changes and seepage characteristics of shale rocks different fracture lengths are shown in Figure 3. In Figure 3(a), the permeability of shale rock increases with the length of the internal fractures in the rock. By fitting the relationship between fracture length and permeability, it is found that the two parameters show a good exponential relationship in the selected range, which indicates that the fracture width plays a decisive role in the permeability variation of shale rock. In addition, when the fracture length in the shale rock is about $1 \mathrm{~cm}$, the permeability of shale rock after fracturing is about three times of the initial permeability. In consideration of the strong stress sensitivity of shale rock, the seepage laws of different fracture lengths in this experiment are evaluated under low pressure conditions, as displayed in Figure 3(b). It is obvious that the larger the internal fracture length, the closer the fitted seepage curve to the origin, implying that the macroscopic flow keeps in line with Darcy law. In other words, a certain pressure needs to be overcome to allow the gas to flow in the porous medium in the initial stage. The main reason is that the existence of fractures reduces the seepage resistance
[28]. The longer the fracture length, the greater the reduction in resistance to gas flow in porous media. Compared with shale own length of $4.04 \mathrm{~cm}$, the fractures with a length of $3.15 \mathrm{~cm}$ cover almost the entire flow channel, which makes it easy to pass through the entire porous medium.

\subsection{Effect of Internal Microfracture Width on Seepage} Characteristics of Shale Rock. As shown in Figure 4, the permeability changes and seepage characteristics of shale rock with different fracture widths are compared under the same fracture length condition. In Figure 4(a), it is obvious that the permeability of shale rock increases sharply with the fracture width. There is a good exponential relationship between fracture width and permeability. In comparison with the initial permeability, it is found that the influence of fracture width on permeability is more serious than that of fracture length. In addition, the permeability of the two shale rocks numbered Ls1-2-2 (0.1521 mD) and Ls2-6-5 (0.0028 mD) after fracturing are relatively close. Compared with the fracture parameters, it can be found that the fracture length is basically the same, and the fracture width is slightly different. However, the permeability of the former is increased by about 8 times, while the permeability of the latter is changed by about 438 times, which sufficiently proves the importance of fracture width to permeability variations of shale rock. The seepage characteristic curves of shale with different fracture widths are shown in Figure 4(b). Similarly, the smaller the fracture width, the more the seepage curve deviates from the origin, and the more obvious its nonlinear permeability characteristics [29]. The main reason is that the fracture width alters the seepage volume of shale rock, while the seepage trajectory is the extended by fracture length. The fracture width reduces the seepage resistance far beyond the fracture length in porous media, which is similar to adding proppant to expand the seepage channel $[9,11]$. In terms of the permeability variation of shale rock, the investment cost 


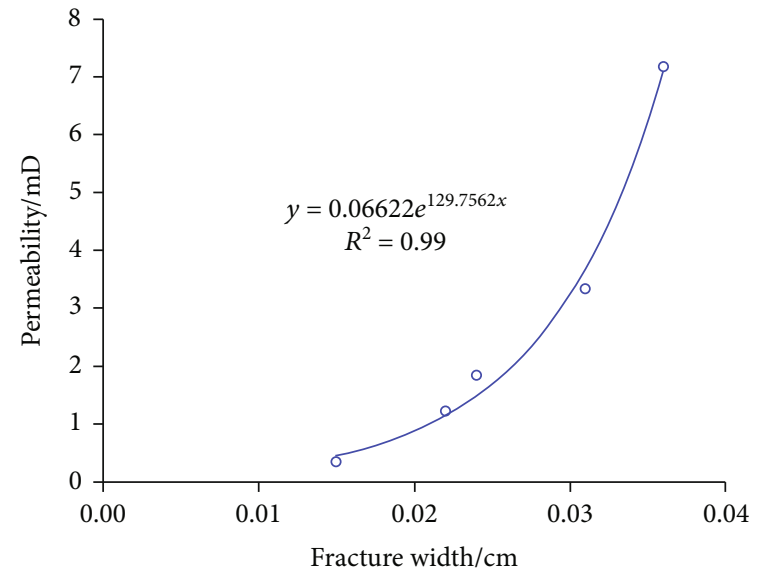

- Experimental point

_ Fitting curve

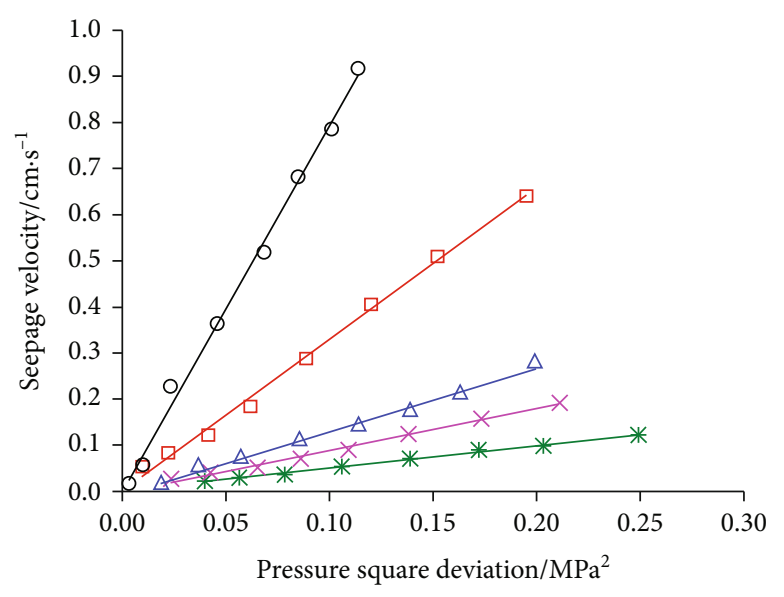

$\begin{array}{ll}* 0.015 \mathrm{~cm} & \square 0.031 \mathrm{~cm} \\ \times 0.022 \mathrm{~cm} & \quad 0.036 \mathrm{~cm} \\ \Delta 0.024 \mathrm{~cm} & \end{array}$

(b)

FIGURE 4: Influence of fracture width on permeability of shale rock: (a) relationship between fracture width and permeability; (b) seepage characteristics of shale rock with different fracture width.

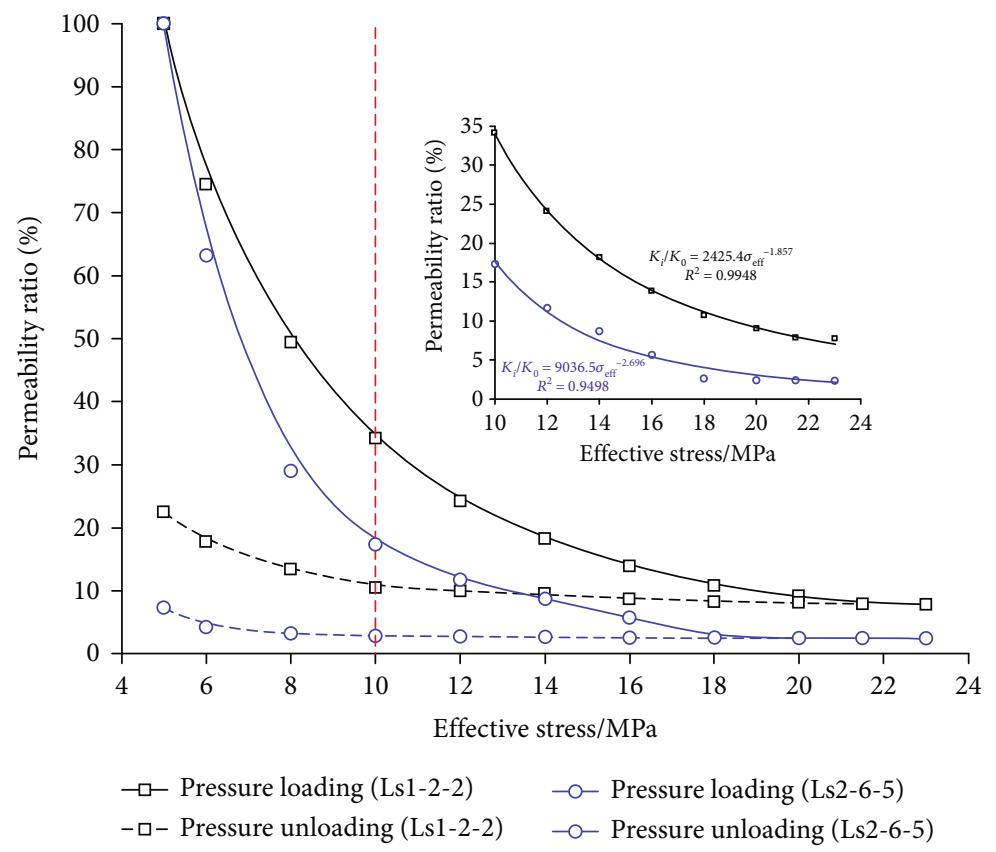

FIGURE 5: The relationship between effective stress and permeability ratio of shale rock with different initial permeability in various pressure stages.

and implement difficulty of the fracture width exceed these of the fracture length in the field exploitation.

3.3. Effect of Internal Microfracture on Pressure-Dependent Permeability of Shale Rock. In general, two shale rocks with different initial permeability can be transformed into two samples with similar permeability, and their main fracture parameters are relatively similar. To study the stress sensitivity characteristics after fracturing from different initial permeability, two shale rocks with permeability of $1.219 \mathrm{mD}$
(No. Ls1-2-2) and $1.228 \mathrm{mD}$ (No. Ls2-6-5) are selected as target. In addition, according to the burial depth of shale reservoir, the primitive effective stress is approximately $10 \mathrm{MPa}$ [14].

The stress sensitivity characteristics of two shale rocks with similar permeability are shown in Figure 5. In the pressure stage, it is obvious that the permeability ratio first decreases rapidly and then tends to be flat with the increase of effective stress. During the whole pressurization stage, the permeability of shale rock with larger initial permeability 
decreases by $90.2 \%$, which is fewer than that of shale rock with smaller initial permeability (97.3\%). When the effective stress increases from $10 \mathrm{MPa}$ to $23 \mathrm{Ma}$, the permeability of shale rock with smaller initial permeability decreases by $26.4 \%$, which is about twice of that of shale rock with smaller initial permeability (14.9\%). In addition, it can be found that the actual effective stress has a good power function relationship with the permeability variation in the selected range. In the initial stage, the microfractures in the rock are gradually closed with the increase of effective stress, which leads to the partial loss of the main contribution to induce permeability [3]. In the later stage of effective stress increase, elasticplastic deformation mainly occurs in the shale rock, and the shale framework particles might change. In addition, the permeability of shale rock generally originates from nano/ micron pores, so the permeability of shale rock with large initial permeability decreases sharply under the influence of external force [27]. The main reason is the difference of fracture width inside the rock. In the pressure unloading stage, the permeability of shale rock with larger initial permeability is restored by $14.7 \%$, while that of shale with smaller initial permeability is only restored by $5.2 \%$, which is mainly due to the irreversible deformation of fractures in shale rock $[15,16]$. After a cycle of effective stress variation, the permeability of shale rocks with large initial permeability and small initial permeability is $0.274 \mathrm{mD}$ and $0.0908 \mathrm{mD}$, respectively. Compared with the initial permeability of the shale rock, the permeability of the rock sample is still improved, mainly because of the new bedding fractures induced by the stress variation [30].

\section{Conclusions}

Through Brazil splitting test, ten fractured shale rocks are carefully selected to study the influence of fracture length and fracture width on shale permeability. Under the condition of low pressure, the seepage characteristics of shale rocks with different fracture length and fracture width are investigated in depth. In addition, two shale rocks with different initial permeability and similar fracturing parameters are selected to study their stress sensitivity characteristics in the selected pressure range.

After artificial fracturing, there is a good exponential relationship between fracture length and shale permeability after fracturing, when the fracture width in the rock is similar. Likewise, the fracture length is the same, and the fracture width also has a good exponential relationship with shale permeability after fracturing. The contribution of fracture width to the increase in permeability exceeds than that of fracture length. In addition, the smaller the fracture width and fracture length, the more prominent the nonlinear seepage characteristics of shale rock. For the two shale rock with similar permeability after fracturing, the permeability of shale rock with large initial permeability decreases by $26.4 \%$ in the selected pressure stage, which is about twice of that of shale with small initial permeability (14.9\%). The main reason for this phenomenon is the difference of fracture width inside the shale rock. In the pressure unloading stage, the permeability of the rock sample with large initial perme- ability recovers by $14.7 \%$, which is about three times of that of the rock sample with small initial permeability (5.2\%). After a cycle of effective stress variation, the permeability of two shale rocks is still improved in comparison with the initial permeability, mainly because of the new bedding fractures induced by the stress variation. Furthermore, exploring the influence of fracture direction on shale seepage characteristics is the primary objective of our next research.

\section{Data Availability}

The data used to support the findings of this study are included within the manuscript.

\section{Conflicts of Interest}

The authors declare that they have no conflicts of interest.

\section{Acknowledgments}

The work is supported by the National Natural Science Foundation of China (Grant No. 11602221).

\section{References}

[1] J. Deng, W. Zhu, and Q. Ma, "A new seepage model for shale gas reservoir and productivity analysis of fractured well," Fuel, vol. 124, pp. 232-240, 2014.

[2] J. W. Carey, Z. Lei, E. Rougier, H. Mori, and H. Viswanathan, "Fracture-permeability behavior of shale," Journal of unconventional oil and gas resources, vol. 11, pp. 27-43, 2015.

[3] Q. Gao, S. Han, Y. Cheng, Y. Li, C. Yan, and Z. Han, "Apparent permeability model for gas transport through micropores and microfractures in shale reservoirs," Fuel, vol. 285, p. 119086, 2021.

[4] D. Zhang, Y. Dai, X. Ma et al., "An analysis for the influences of fracture network system on multi-stage fractured horizontal well productivity in shale gas reservoirs," Energies, vol. 11, no. 2, p. 414, 2018.

[5] Y. Xue, Y. Wu, L. Cheng, S. Huang, S. Ai, and Y. Yang, “An analytical model for multiple fractured shale gas wells considering fracture networks and dynamic gas properties," Arabian Journal of Geosciences, vol. 11, no. 18, p. 551, 2018.

[6] T. Wang, S. Tian, W. Zhang, W. Ren, and G. Li, "Production model of a fractured horizontal well in shale gas reservoirs," Energy \& Fuels, vol. 35, no. 1, pp. 493-500, 2021.

[7] T. Guo, S. Zhang, J. Gao, J. Zhang, and H. Yu, "Experimental study of fracture permeability for stimulated reservoir volume (SRV) in shale formation," Transport in Porous Media, vol. 98, no. 3, pp. 525-542, 2013.

[8] Y. Meng, M. Li, X. Xiong et al., "Material balance equation of shale gas reservoir considering stress sensitivity and matrix shrinkage," Arabian Journal of Geosciences, vol. 13, no. 13, pp. 1-9, 2020.

[9] Y. Tan, Z. Pan, J. Liu, X. T. Feng, and L. D. Connell, "Laboratory study of proppant on shale fracture permeability and compressibility," Fuel, vol. 222, pp. 83-97, 2018.

[10] M. Yue, X. Huang, F. He, L. Yang, W. Zhu, and Z. Chen, "Analysis of the influence of different fracture network structures on the production of shale gas reservoirs," Geofluids, vol. 2020, 11 pages, 2020. 
[11] M. Yue, Q. Zhang, W. Zhu, L. Zhang, H. Song, and J. Li, "Effects of proppant distribution in fracture networks on horizontal well performance," Journal of Petroleum Science and Engineering, vol. 187, p. 106816, 2020.

[12] M. Chen, Y. Lu, Y. Kang et al., "Parameters selection for experiment on aqueous phase trapping damage in shale gas reservoirs," Journal of Natural Gas Science and Engineering, vol. 83, p. 103551, 2020.

[13] R. Heller, J. Vermylen, and M. Zoback, "Experimental investigation of matrix permeability of gas shales," AAPG Bulletin, vol. 98, no. 5, pp. 975-995, 2014.

[14] Z. Song, H. Song, D. Ma, W. Zhu, and J. Yu, "Morphological characteristics of microscale fractures in gas shale and its pressure-dependent permeability," Interpretation, vol. 5, no. 1, pp. SB25-SB31, 2017.

[15] C. Yin, "Test and analysis on the permeability of induced fractures in shale reservoirs," Natural Gas Industry B, vol. 5, no. 5, pp. 513-522, 2018.

[16] D. Yang, W. Wang, K. Li, W. Chen, J. Yang, and S. Wang, "Experimental investigation on the stress sensitivity of permeability in naturally fractured shale," Environmental Earth Sciences, vol. 78, no. 2, p. 55, 2019.

[17] G. Cui, J. Liu, M. Wei, X. Feng, and D. Elsworth, "Evolution of permeability during the process of shale gas extraction," Journal of Natural Gas Science and Engineering, vol. 49, pp. 94$109,2018$.

[18] Y. Zhao, C. Wang, and J. Bi, "Permeability model of fractured rock with consideration of elastic-plastic deformation," Energy Science \& Engineering, vol. 8, no. 2, pp. 441-451, 2020.

[19] Y. Li, P. Dong, and D. Zhou, "A dynamic apparent permeability model for shale microfractures: coupling poromechanics, fluid dynamics, and sorption-induced strain," Journal of Natural Gas Science and Engineering, vol. 74, p. 103104, 2020.

[20] B. Jia, L. Jin, B. A. Mibeck, S. A. Smith, and J. A. Sorensen, “An integrated approach of measuring permeability of naturally fractured shale," Journal of Petroleum Science and Engineering, vol. 186, p. 106716, 2020.

[21] X. P. Zhou and Z. Zhao, "Digital evaluation of nanoscale-pore shale fractal dimension with microstructural insights into shale permeability," Journal of Natural Gas Science and Engineering, vol. 75, p. 103137, 2020.

[22] Y. Guo, C. Yang, L. Wang, and F. Xu, "Effects of cyclic loading on the mechanical properties of mature bedding shale," Advances in Civil Engineering, vol. 2018, Article ID 8985973, 9 pages, 2018.

[23] D. Chen, Z. Pan, and Z. Ye, "Dependence of gas shale fracture permeability on effective stress and reservoir pressure: model match and insights," Fuel, vol. 139, pp. 383-392, 2015.

[24] G. Cui, J. Liu, M. Wei, R. Shi, and D. Elsworth, "Why shale permeability changes under variable effective stresses: new insights," Fuel, vol. 213, pp. 55-71, 2018.

[25] J. Zhou, L. Zhang, X. Li, and Z. Pan, "Experimental and modeling study of the stress-dependent permeability of a single fracture in shale under high effective stress," Fuel, vol. 257, p. $116078,2019$.

[26] H. Chen, T. Zhou, H. F. J. Zhang, and S. Yang, "Preparation method and stress sensitivity of core samples with hydraulic fractures in shale reservoirs," Acta Petrolei Sinica, vol. 41, no. 9, pp. 1117-1126, 2020.
[27] W. Zhu, D. Ma, H. Zhu, L. An, and B. Li, "Stress sensitivity of shale gas reservoir and its influence on productivity," Natural Gas Geoscience, vol. 27, no. 5, pp. 892-897, 2016.

[28] D. S. Berawala and P. Ø. Andersen, "Numerical investigation of non-Darcy flow regime transitions in shale gas production," Journal of Petroleum Science and Engineering, vol. 190, p. 107114, 2020.

[29] Z. Shen, L. Zhou, X. Su, H. Li, J. Tang, and X. Zheng, “An experimental investigation of the nonlinear gas flow and stress-dependent permeability of shale fractures," Energy Science \& Engineering, vol. 8, no. 8, pp. 2808-2822, 2020.

[30] J. Zhong, S. Liu, Y. Ma et al., "Macro-fracture mode and microfracture mechanism of shale," Petroleum Exploration and Development, vol. 42, no. 2, pp. 269-276, 2015. 